\title{
Does Social Media Promote Civic Activism? A Field Experiment with a Civic Campaign
}

\author{
Florian Foos* \\ London School of Economics \& Political Science \\ Lyubomir Kostadinov \\ University of Sofia \\ Nikolay Marinov \\ University of Houston \\ Frank Schimmelfennig \\ ETH Zurich
}

\begin{abstract}
Social media may help civil society organize and mobilize for different campaigns. However, the extent to which social media campaigns simply recruit like-minded individuals as compared to exerting a causal impact on joiners' attitudes is difficult to disentangle. We test both the organizational and transformative potential of a civil society campaign in a randomized field experiment deployed via Facebook or an email newsletter in collaboration with a Bulgarian environmental campaign. As expected, we find that Bulgarian Facebook users who are active in pro-environmental groups, and those who decide to follow the campaign, are more highly educated than those who decide to stay at the sidelines. Moreover, beliefs in the effectiveness of civic society, character traits, and prior activism systematically predict whether a Bulgarian Facebook user decides to join the cause on Facebook, or subscribe to the email newsletter. In contrast, we find little evidence that the campaign affected opinions, knowledge, or self-reported behavior. We conclude that social media campaigns that are commonplace among civil society organisations are effective at selecting activist-types, but changing the views and behaviors of the broader social media population may be more difficult than assumed.
\end{abstract}

${ }^{*}$ We thank Don Green, Alex Coppock, Dingeman Wiertz, Anna De La O, Peter Aronow, Andreas Landmann, Björn Vollan, and Moritz Marbach for helpful comments and advice. We would also like to express our gratitude to three anonymous reviewers and to the Associate Editor, Rocio Titunik, for improving this paper during the review process. This project would not have been possible without the cooperation of the NGO-community in Bulgaria. We are grateful to Alpha Research for their professional and dedicated polling services. We also thank Kaloyan Petrov (Designolog) and our research assistant, Nina Dyakova. Finally, we are grateful to the Cooper Fund, ETH Zürich, for financial support of the project. Email contacts: f.foos@lse.ac.uk, kostadinov.lyubomir@gmail.com, Nmarinov@central.uh.edu, frank.schimmelfennig@eup.gess.ethz.ch 


\section{Introduction}

Growing links to social media are a notable feature of contemporary civic activism. Dramatic events in the Arab world, Ukraine and Turkey have taken place against the backdrop of intense internet-sharing activity by participants (Anderson, 2011; Tufekci and Wilson, 2012; Jost et al., 2018). There are many other, less dramatic examples, of relying on social media to broadcast a message, build awareness or organize for a cause (Jost et al., 2018). They include social movement campaigns, extensions of traditional non-governmental organizations into the blogosphere, and smaller-scale civic campaigns. How do online social networks, understood as people communicating with people, help civic forms of political engagement emerge, and how do they help to sustain them?

In principle, digitally-linked social networks can help overcome two main difficulties confronting civic activism: identifying supporters in a large and diffuse group of people on an issue of common concern, and helping supporters move closer to achieving the goals of the cause (Olson, 1971). Whether used in isolation or as a complement to traditional means of conducting campaigns, one may expect social media to increase grass-root engagement with social and political issues in local, national and global communities.

Existing arguments posit that online social networks help bottom-up civic activism via three broad mechanisms: information diffusion, social influence, and critical mass dynamics (González-Bailón, 2014). Reliable information on an issue is critical for progress on a cause. Social discussions, interpersonal trust and the various selective benefits and incentives that accrue in social networks may prove motivational and even transform an individual's view on an issue. Critical mass dynamics refer to strength in numbers, the idea that networked technology can build awareness of the strength of a cause, and change motivations for acting based on the idea that success is imminent. 
We build on existing arguments about the role of social networks for political and civic activism (Bode et al., 2014) to develop a series of testable hypotheses, and we then embed a field experiment in a civic campaign to test them. Our case is drawn from Bulgaria. The case involves a civic campaign to protect the remaining Black Sea beaches from, often illegal, development.

Uncovering the existence of attitudinal or behavioral patterns in an online social network would be of limited value, unless we can contrast these patterns with the counterfactual patterns that would be observed were the networked or online element absent (Fowler et al., 2011). Thus, in order to identify the added value of the networked element, we need to compare citizens who would be exposed to political information via social media to citizens who would not be exposed to such information, and citizens who would be exposed to that information via different means of communication. The major issue is that citizens self-select into social networks, and it is hence difficult to disentangle selection from influence.

By construction our study can relate members of activist Facebook pages to some meaningful population of interest. We recruit two different samples. One sample is drawn from the proenvironment activist population in Bulgaria, and the other is a representative sample of Bulgarian Facebook users recruited via a traditional in-person survey. In both samples, we encourage a randomly assigned share of respondents to enroll in a campaign to protect natural resources. Thus, we observe who, among those encouraged to join, elects to join. In this way, we can re-create a part of the process of selection that occurs on social media. In combination with the background information collected on respondents, this allows us to profile the type of people who respond to invitations to contribute to civic causes on online social media. Because we randomly assign citizens to three experimental conditions, an encouragement to like a Facebook page, to sign-up to an email newsletter, or to control, the groups receiving an encouragement are ex-ante comparable to the control group. Thus, we can ultimately 
identify the causal effects brought about by the use of social media as a civic instrument. The few previous studies that randomly assigned citizens to social media influence via Facebook provide mixed evidence on whether Facebook positively affects political engagement (Bond et al., 2012; Theocharis and Lowe, 2016).

We find that social media are effective in selecting potential proponents of a cause. The people who select themselves into civic campaigns via the network tend to have different personalities (more adventurous), care more about the issue (nature), and are more likely to have engaged in activism prior to the campaign than respondents who decide not to follow the campaign. Thus, selection effects produce a potentially potent brew of like-minded, active people. In that sense, our results parallel findings showing that like-minded people gravitate toward each other on Facebook (Bakshy, Messing and Adamic, 2015), and that they select into the same news channels (Arceneaux and Johnson, 2013). However, a campaign conducted via Facebook does not appear more selective than a campaign conducted via a more traditional email newsletter. This is probably less of a surprise than we expected given the widespread use of Facebook in Bulgaria, and elsewhere.

Beyond that, our results suggest that such a campaign does at best have minimal effects on attitudes, and does not substantially transform what followers believe about the cause or think of their civic activism. Overall, we find little evidence that the campaign mobilized people to become active or to discuss the cause more with friends online. We even uncover some darker overtones: people who followed the Facebook campaign were less likely to think that environmental activism was appreciated by others. Email newsletters appear to be generally ineffective for most of the outcomes we measure. In sum, we find that the media we study produce self-selected communities. While these may play an oversized role at key junctures, there is little evidence that they change how members think on an everyday basis. 
These findings speak to the broader debate on the influence of the Internet on civic engagement. Boulianne (2015)'s meta analysis reports that social media use is positively correlated with participation, but that questions remain on whether the relationship is causal and transformative. We find that the relationship is not transformative, but that the civically active select themselves into social media campaigns.

\section{Social Media and Civic Campaigns}

We define social media as a subset of new digital communication technology with peerto-peer access. A more precise definition in the literature has been elusive. As Gohdes (2014, 17) writes: “... digital communication technology and new digital media are seldom clearly defined, but generally they include the usage of peer-to-peer online platforms, such as Facebook, Instagram, Youtube, and Twitter, and voice over internet provider services (VoIP, such as Skype)" . We focus on one of the most popular social media services, Facebook. The ubiquity of the service in many parts of the world, together with the interactive, peer-to-peer nature of the medium is key for our purposes.

Studies on voter turnout in democracies have used experimental methods to identify a causal effect between seeing socially-shared content and electoral participation (Bond et al., 2012; Messing, Bakshy and Fiore, 2014). However, beyond anecdotal and journalistic accounts, there is little evidence to date that social media messages affect political attitudes or behaviors beyond turnout (Broockman and Green, 2014). This mixed picture is well illustrated by Coppock, Guess and Ternovski (2016)'s results who find that publically posted messages on Twitter did not affect online sharing behavior related to a political cause, while private messages did. 
Other studies have looked more explicitly at self-selection into social networks such as Facebook (Bakshy, Messing and Adamic, 2015) and Twitter (Barberá et al., 2015). Bakshy, Messing and Adamic (2015) find that Facebook users befriend others who are more likely to share their political outlook, and Barberá et al. (2015) show that discussions of political events on Twitter lead to relatively homogeneous retweet networks, especially if the nature of the discussion is more partisan. There is therefore evidence that selection effects are important when we try to understand political activism on social media. At the same time, both studies emphasize that political homogeneity is far from complete, and that there is room for social influence. There is disagreement on whether social networks aggravate polarization (Settle, 2014), or help reduce it (Barberá, 2014). Civic movements in authoritarian regimes have benefited from digital media, even though the more skillful authoritarian regimes such as Russia and China have striven to co-opt peer-to-peer online networks for regime survival (Gunitsky, 2015).

Existing evidence on the effectiveness of email campaigns in changing behaviors is equally

mixed. Nickerson (2007) shows that email is ineffective at boosting voter turnout, while Han (2016) provides some evidence for the effectiveness of email in mobilizing members of an organisation, the National Association of Doctors, to sign a petition. However, recent evidence from the US also suggests that emails that urge email subscribers to pay attention to a specific local political issue might backfire and make citizens less, not more, likely to pay attention to that issue (Butler and Hassell, 2018).

\subsection{The networked benefits for civic activists}

Identifying other people with similar interests is an enduring problem confronting civil society groups. By allowing members to choose, or self-select membership by interest, social media 
such as Facebook allow people to more easily build communities. In the case of specific campaigns, centered around a single issue or an array of related issues, the advantages of social media stand out even more clearly. Facebook pages promote a specific cause of interest to a specific set of people. Seeing that others, especially friends, have joined is an additional factor of attraction. Expectations about the possibilities of networked technology may also exert a pull.

Online networked communities dedicated to a cause are likely to attract certain types of people. Research in psychology shows that some people are more likely to take the initiative and lead (Verplanken and Holland, 2002). Margetts et al. (2016, 2015) demonstrate that personality type is an important predictor of social media activism. They argue that citizens who are more open to experience should be more likely to cross the threshold of social media activism (Margetts et al., 2016). Moreover, research on personal values and decisions shows that action on congruent values is more likely when people perceive values central to their well-being. People who care deeply for a cause are more likely to be attracted to a community fighting for it (Margetts et al., 2015; Vaccari et al., 2015).

Information is a necessary condition for success on a common cause (Lieberman, Posner and Tsai, 2014). By design, social networks facilitate the flow of information. In countries where traditional media and other outlets of information are known to be poor sources of politically-relevant and credible information, social media can assume outsized importance. The low costs of entering the media market via social media means anyone enthusiastic enough can start providing information. Whereas other information sources may need to address a wider set of issues, a network community of interest can choose to zero in on a common cause. This may increase knowledge about the object of the campaign.

Being embedded in a social network can create various side-effects that may be beneficial 
for a cause. The relative visibility of acting within a network can create a variety of possible benefits to personal involvement (Klandermans, 2002). Social-esteem and peer-pressure, are more likely to be operative in a network setting, where others know about one's actions (Gerber and Larimer, 2008).

Less tangible benefits of community include a feeling of belonging and of dedication. Individuals participating in campaigns desire social recognition, a sense of belonging to a group (Kitts, 2000), or a common cause (Goodwin, 1997) to motivate them to pay the costs of participating. Sharing one's opinion online can work differently depending on whether one is involved in a community or not. People can thus become more engaged because their opinion matters to others, increasing the importance of the issue to the participant.

Our study builds on Bennett and Segerberg (2012)'s seminal distinction between collective and connective action. In some ways, our research focus is primarily on how adding a social media aspect to a campaign could help overcome collective action problems, by, for example, incentivizing members to join a protest. Critical mass dynamics, or coordinated effort is central for a group's success (Klandermans and Oegema, 1987). Social media are well-suited for that purpose: people receive information about the intentions of others, and can set their actions in response to the anticipated behavior of others. Collective action such as formulating and sharing a common position e.g. via petitions, and holding rallies and protests, is the holy grail of civic activism. Protest can lead to change (Bratton and van de Walle, 1992), and contentious politics helps social interests achieve representation (Tarrow, 1998). An online community comprised of many people is more likely to receive support from other groups and make an impression on official authorities. 


\subsection{The civic role of social media in façade democracies}

The importance of social media for civic causes may vary according to the opportunities provided by the system for grievance redress. In established democracies, civic associations, well-functioning party networks and working state institutions better ensure that political choices broadly reflect grassroots social preferences (Putnam, 2000). However, countries such as Bulgaria, Turkey, and Ukraine that have transitioned to democracy more recently, feature a veneer of political freedoms, while governments also cater to special interests. Many Eastern European countries have weak civil society associations (Howard, 2003). Political parties are non-programmatic, and there are no neighborhood clubs and organizations, which make social media all the more relevant for civic activism.

In façade democracies, or hybrid regimes (Diamond, 2002), special interests hollow out institutions. Traditional media are easily silenced, and existing institutions lose credibility with the public. Overtime, the politics of corruption multiplies popular grievances. Thus, a market is created for new ways of doing things. Informal institutions arise, assuming counter-culture overtones of resistance, centered around communities of creative defiance. In façade democracies, politics often happens online. Citizens can act as journalists to quickly reach like-minded supporters via point-to-point networks. Others can contribute information. When little (or fake) debate is allowed in news outlets, social media become a focal point.

Table 1 summarizes data from European democracies on views of social media as a platform to have one's voice heard on political issues. ${ }^{1}$ The data indicate that in younger European democracies, people believe that their voice is not really heard in the political system - and, at the same time, they are more likely to recognize online social media as a potential tool to

\footnotetext{
${ }^{1} 4$-points scale collapsed into agree/disagree. The source is Eurobarometer 78.1, 2012.
} 
redress grievances the system does not meet. Similar gaps do not exist in Western Europe. Our findings speak most directly to the set of cases that have these characteristics.

Table 1: Voice Heard: Traditional Politics and Social Media

\begin{tabular}{|r|r|r|}
\hline \hline & $\begin{array}{r}\text { My voice is heard } \\
\text { in political system }\end{array}$ & $\begin{array}{r}\text { Online social networks } \\
\text { give me say on issues }\end{array}$ \\
\hline Bulgaria & 0.44 & 0.88 \\
Czech Republic & 0.30 & 0.62 \\
Poland & 0.56 & 0.73 \\
Latvia & 0.31 & 0.79 \\
Finland & 0.81 & 0.77 \\
Germany (W) & 0.74 & 0.61 \\
Netherlands & 0.81 & 0.63 \\
France & 0.79 & 0.60 \\
\hline
\end{tabular}

As governments in façade democracies are at least nominally committed to individual rights and freedoms, network disruptions to stop or harass civic activists are difficult or impossible. A recent quantitative study found that Sweden, an advanced democracy, shuts down the internet more often than Bulgaria, a façade democracy (Howard, Agarwal and Hussain, 2011). In façade democracies, therefore, we expect social media to play an outsize role for civic activism. Unlike the case of authoritarian regimes, such as Egypt, where the main objective of citizen activists is to bring down the government, in façade democracies the issues are classic collective-goods problems: keeping a patch of the city green such as in Gezi Park, Istanbul (Tufekci, 2017).

\subsection{Hypotheses}

We next outline our hypotheses. Our main interest lies in showing the effects of a networked digital campaign on attitudes and perceptions related to civic activism and the cause being 
championed. We can contrast a campaign conducted on social media to the no campaign case and show that social media add some value. However, it would be more instructive to also include a non-networked digital technology, such as email, among the experimental groups. We do so by conducting a campaign via email newsletters.

If our arguments about the network are correct, non-networked digital communication technologies should be unlikely to have similarly strong effects. Deprived of the dynamic, interactive environment, digital communications should not exert a comparable pull, nor produce the same effects. Since email and Facebook will provide the same information, if what is at work is information, we expect to see the same patterns among subjects enrolled in either. If $\mathrm{FB}$ differs, it must be that some feature of the social network is at play - the ability to share, or to have others share what you have shared.

In addition to its theoretical value, our comparison has important practical applications. Many campaigns are currently conducted via email newsletter, and organizers may want to probe the efficacy of a medium, that only guarantees that the message is conveyed. Social media convey information but also links the recipients.

Hypothesis 1 An online social network civic campaign will attract disproportionately people with predispositions for the cause, risk-acceptant personality traits and activist profiles (i), a selectivity effect that will be stronger for networked than for non-networked online communication technologies (ii).

Hypothesis 2 Campaigns conducted via online social networks will result in information-diffusion, will increase social engagement of participants around the issues, and will increase perceptions of success in terms of achieving the objective of the campaign (i), effects that will be stronger for networked campaigns than for campaigns involving non-networked online communication technologies (ii). 


\section{Embedding an experiment in a campaign-rollout}

Studying the impact of social media on bottom-up politics has traditionally been plagued by a methodological problem: "Even the most trenchant empirical contributions have been saddled thus far with limitations, such as the unrealistic assumption that 'users joined the movement the moment they started sending Tweets about it" Jost et al. (2018, 86). It is difficult to distinguish and separate selection from causality (Fowler et al., 2011). Campaigns, online or not, are neither created, nor joined randomly. In a typical example, a researcher would observe a Facebook page and offline activity by people linked to the site. One may be tempted to infer that social media were an effective means of mobilizing people. The problem is that the researcher does not observe a world where organizing via social media was unavailable or where the campaign was conducted via another medium. We address this problem with the use of a field experiment. In our experiment, we use the rollout of a campaign to randomize the eligibility of people to enrol in a Facebook-coordinated campaign or in an email-coordinated campaign for a cause. The control group receives no invitation.

Our case is drawn from Bulgaria. The case involves a civic campaign to protect Black Sea beaches from (often illegal) development. Environmental causes are popular, yet ruling parties have done little to ensure that private development is consistent with the law or the public interest. The threats to nature in Bulgaria are many. Perhaps foremost among them is the ability of special interests to take over land for commercial development while circumventing the country's legislative requirements for local and national review of development plans. The country's legal system is weak and seldom indicts suspected malfeasance. Public opinion holds many cases of rezoning in natural parks to be deliberate, possibly illegal, and in the service of the select few over the public interest.

Ours is a campaign of civic vigilance. Nature - underdeveloped beaches, dune-associated flora 
and fauna - are a resource, to be enjoyed and passed on to future generations. Bulgaria's post-communist elite has proved adept at finding smaller or bigger doors in the country's legislative and administrative institutions to privatize public land and to develop it, for substantial personal gain. One mechanism, for example, is to say that the law protects dunes against development, but also to spend 20 years to produce a map of the dunes. This leads to paradoxical developments such as heavy machinery ploughing away dunes, while the controlling agencies give interviews in front of the melting dunes to explain that the dune is not on a map as the law required and so 'this was not a dune'. In this setting, social media help civic society in the following way. Campaigns form around resources at risk. If and when an encroachment is noticed, people begin an aggressive campaign of sharing pictures and notes about the violation. If the uproar is sufficient, the country's populist leaders step in and 'personally' stop the development. This mechanism can stop encroachments before they have advanced enough to reach a critical point of no return. ${ }^{2}$ Key to this mechanism is user connectivity and personal initiative. For example, pages coordinating such activities need to pick up a photo and spread the message quickly. Our experimental setup allows for peer effects: even though the encouragement to join the Facebook page does not come from a friend, if and when one shares a picture or comments, friends are engaged and messages spread.

\subsection{Experimental setup}

The campaign in which we embedded our experiment was called ZaMoreto, "For the sea". We randomly assigned subjects to receive an encouragement to take one of the two treatments

\footnotetext{
${ }^{2}$ For a typical case, consider the archaeological reserve site Yailata. Without publicity, local businessmen acquired papers to build on the rocky coast of the preserve. Development began suddenly and proceeded briskly. Quickly, images circulated on social media and an online community was formed to help stop the building, pending review. After three days, authorities issued a stay on the building permit. On Facebook, people continued to investigate until the authorities ruled the permit illegal.
} 
(to like the Facebook page or to sign-up to an email newsletter), or not to receive any encouragement. People received the same or very similar information via email as they did via the Facebook page, but they did not have access to the interactive, networked features social media offer. Hence, what differs between them is that one is a non-networked digital campaign, and the other, a campaign involving an online social network. The Facebook page we relied on for the Facebook campaign, ZaMoreto was newly-launched and had a small following (about 200 likes) by the time people got the encouragement. Moreover, while the page was set up in cooperation with members of the activist community, their involvement was informal and low-key. We would define the campaign as a leaderless campaign, centered on a common cause. As such, this is a very typical example of the contemporary social media landscape.

Because assignment to the social media and newsletter groups is random, any systematic post-treatment differences between the groups will likely be due to the campaign and the means of conducting it. Our campaign is set-up in ways that mirror some of the basic choices many or most people would typically have to make when contemplating the launch of a civic campaign. In terms of the sheer popularity of the two means of promoting civic causes via different electronic media, email newsletters and Facebook are by far the two most popular choices. Thus, this comparison speaks directly to a very practical choice involved in the lives of a large number of civic campaigns.

\subsection{Recruitment, assignment and outcome measurement}

During the first stage, we chose to recruit subjects via two channels. First, a professional polling agency approached 3,332 subjects between the ages of 18 to 60 that were sampled randomly within all Bulgarian towns with population of 50,000 or more. A filtering question 
made sure that only people with Facebook accounts received invitations to participate in the study. Subjects were dispersed around the country, and represented a tiny proportion of all Facebook users. As a result we do not believe they were connected in any way among themselves at the start of the experiment. Since Facebook use is wide-spread in Bulgaria (between $1 / 2$ and $2 / 3$ of all Bulgarians are on the social network), our sample is representative of a large and growing part of the Bulgarian population. At this stage, the polling agency recorded basic demographic information and views about the environment, afterwards we used Bernoulli (simple) random assignment to allocate subjects to one of three experimental conditions, with resulting probabilities of .34 (Facebook condition), .34 (newsletter condition) and .32 (control). ${ }^{3}$

The research team then emailed all subjects in the representative sample if they would participate in our study, register in the online panel and answer questions online. The first online survey wave included questions about views on the environment and some information on social attitudes and political behavior. A total of 527 out of 3,332 subjects confirmed participation in the study and answered the first wave of the questionnaire. We refer to this group as the representative sample, reflecting the manner of its recruitment, and distinguishing it from our second sample, a sample of environmental activists. For that, we posted a widget on the Facebook page of the NGO-umbrella organization ZaDaOstanePriroda (SoThatNatureRemains), an existing page with 20,000 "likes". ${ }^{4}$ Users were invited to take part in a study, and 648 environmental activists filled in the baseline questionnaire with demographic information, and views of the environment. Afterwards we used again Bernoulli (simple) random assignment to allocate subjects to one of three experimental conditions, with resulting probabilities of .31 (Facebook condition), .35 (newsletter condition) and .34 (control), and

\footnotetext{
${ }^{3}$ We provide the detailed random assignment protocol in Online Appendix E.

${ }^{4}$ The NGO coalition brings together different organizations with some common goals: preserve natural habitats, conserve national parks, and ensure lawful and sustainable development of Bulgaria's natural resources. The funding is project-based, including from the WWF and EU agencies.
} 
emailed all registered activists the first wave of the online questionnaire, which was answered by 357 respondents. This constitutes our activist sample. Comparing the demographic and attitudinal profile of the activist sample to that of randomly selected Facebook users will give us a sense of how online communities differ from the general population.

Over the next eight weeks, the newly created page was filled with content about specific surviving wild areas around the sea coast, including threats to their survival, and possible strategies for keeping them wild. About 5 posts per week were posted, always including a picture and brief text. The same content was assembled and mailed to subjects in the email newsletter group once a week. We logged activity on the Facebook page, including shares, likes and comments. A snapshot of the page, which has continued to be active, is provided in Figure A6 of the Online Appendix. We also provide a snapshot of a typical email newsletter (see Appendix Figure A7). Moreover, we display a typical post that gained a larger number of likes and shares, including comments by subjects, in Figure A8.

After 8 weeks, we deployed the second wave of the online survey, in which we asked subjects about their views on the state of the environment, the likelihood of success of civic initiatives and other outcome variables. Respondents always received a customized, unobtrusive link that made sure answers were matched to the correct interviewee.

To reduce attrition between the two waves of the online survey, we entered everyone filling out the survey in a raffle with a few small prizes, such as environmentally themed T-shirts and a GPS-walking band. 64 percent of first wave respondents filled in the second wave of the survey.

Participation in the study did not pose risks for participants. All participants were informed about the general area of the study, but were not informed about the research design because that would have undermined our ability to carry out the study's objectives. Participants 
could elect to be updated, upon completion of the study, when a summary of the results was passed on to them. The identity of the respondents was never known to the principal investigators, as a standard confidentiality measure. Upon completion of the study, both the newsletter group and the control group also received invitations to like the Facebook pages of ZaMoreto and ZaDaOstane. The hypothesized benefits of the treatment for civic action could thus accrue to these groups as well.

\section{Results}

One unique feature of our study is that we can say more about the type of respondents selecting into social media campaigns. First, we systematically compare respondents recruited via the representative Facebook sample and those we recuited from the activist Facebook page of the NGO-community ZaDaOstanePriroda. This comparison is observational in nature. It is nonetheless of interest since few researchers have been able to compare the profiles of a dedicated online community to a more representative sample of the online population.

Table 2 and Figure 1 show how a sample of Bulgarian Facebook users compares to a sample of Bulgarian environmental activists on several important attributes, including key demographics, social connectedness, personality traits, attitudes and perceptions, such as love for nature and trust in public institutions, and prior self-reported civic activism. ${ }^{5}$ Our questions on personality traits, and civic activism come from standard batteries used by the European Values Study. ${ }^{6}$

\footnotetext{
${ }^{5}$ We use a 1 to 5 scale of civic activism, composed of the sum of positive answers to the following questions: "There are different ways in which things in Bulgaria can be made better or at least can be prevented from getting worse. In the past 12 months, have you personally 1) ...gotten in touch with a politician $/$ member of the central or local government? 2) ...worked for a political party or an organization? 3) ...worked for another organization or association? 4) ...signed a petition or a public request? 5) ...taken part in a protest or demonstration?"

${ }^{6} \mathrm{http}: / /$ www. europeanvaluesstudy.eu/.
} 


\subsection{How do members of an existing Facebook activist community compare to the general population that uses Facebook?}

Table 2: Covariates that predict belonging to the activist sample over belonging to the representative sample - based on linear regression

\begin{tabular}{|c|c|c|c|c|c|c|}
\hline & $\bar{\beta}$ & SE & $\bar{\beta}$ & SE & $\bar{\beta}$ & SE \\
\hline & \multicolumn{6}{|c|}{ Socio-Demographics } \\
\hline Town population (log) & $0.176^{* * *}$ & 0.013 & $0.115^{* * *}$ & 0.013 & $0.097^{* * *}$ & 0.012 \\
\hline Age & -0.0004 & 0.001 & -0.001 & 0.001 & -0.001 & 0.001 \\
\hline Male & 0.034 & 0.032 & 0.018 & 0.029 & 0.008 & 0.027 \\
\hline University & $0.125^{* * *}$ & 0.032 & $0.078^{* * *}$ & 0.029 & 0.036 & 0.028 \\
\hline \multirow[t]{2}{*}{ Well-off } & -0.039 & 0.032 & -0.019 & 0.029 & -0.006 & 0.027 \\
\hline & \multicolumn{6}{|c|}{ Social connectedness } \\
\hline Number of real-life friends & $0.039^{* * *}$ & 0.014 & 0.018 & 0.013 & 0.002 & 0.012 \\
\hline Number of Facebook friends & $0.039^{* * *}$ & 0.015 & 0.014 & 0.013 & 0.007 & 0.012 \\
\hline \multirow[t]{2}{*}{ Frequency of Facebook use } & $0.057^{* * *}$ & 0.014 & $0.032^{* *}$ & 0.013 & $0.022^{*}$ & 0.012 \\
\hline & \multicolumn{6}{|c|}{ Attitudes and traits } \\
\hline News from TV & \multicolumn{6}{|c|}{ Reference } \\
\hline News from print & & & 0.089 & 0.067 & 0.032 & 0.072 \\
\hline News from social media & & & $0.308^{* * *}$ & 0.031 & $0.234^{* * *}$ & 0.030 \\
\hline Leading role of civil society & \multicolumn{6}{|c|}{ Reference } \\
\hline Equal role & & & $0.054^{* *}$ & 0.027 & $0.046^{*}$ & 0.025 \\
\hline Secondary role & & & 0.103 & 0.070 & 0.065 & 0.063 \\
\hline Trust in institutions & & & $-0.023^{* * *}$ & 0.009 & $-0.021^{* *}$ & 0.009 \\
\hline Environmental knowledge & & & -0.010 & 0.013 & -0.014 & 0.012 \\
\hline Love of nature & & & $0.109^{* * *}$ & 0.016 & $0.071^{* * *}$ & 0.016 \\
\hline Like danger & & & $0.025^{* *}$ & 0.011 & $0.017^{*}$ & 0.010 \\
\hline Like adventure & & & $0.043^{* * *}$ & 0.012 & $0.023^{* *}$ & 0.011 \\
\hline Seek pleasure & & & -0.002 & 0.012 & 0.008 & 0.012 \\
\hline \multirow[t]{2}{*}{ Showcase ability } & & & $-0.030^{* * *}$ & 0.011 & $-0.025^{* *}$ & 0.010 \\
\hline & \multicolumn{6}{|c|}{ Self-reported activism } \\
\hline Civic activism & & & & & $0.060^{* * *}$ & 0.014 \\
\hline Environmental activism & & & & & $0.212^{* * *}$ & 0.032 \\
\hline Frequency of voting & & & & & 0.006 & 0.013 \\
\hline $\mathrm{N}$ & \multicolumn{6}{|c|}{884} \\
\hline
\end{tabular}

Column 1 in Table 2 displays demographics and social connectedness only, while column 2 adds attitudes and personality traits, and column 3 additionally accounts for self-reported 
activism. As one would expect - the respondents recruited via the NGO's page are significantly more likely to be university graduates, and to be more embedded within their social networks. Table 2 also shows that environmental activists are more likely to get their news from social media than the representative sample and more likely to live in larger towns. Importantly, however, they do not markedly differ on self-reported economic status, gender or age. Column 2 shows that respondents recruited via the NGO's page are significantly more likely to love nature, and they are less likely to trust public institutions. Moreover, they are significantly more likely to love danger and adventure than the general population. Finally, as one would expect from the activist sample these differences translate into higher self-reports of civic and environmental activism (column 3).

\subsection{Who joins a campaign if encouraged?}

We know that Facebook pages promoting causes, whether green causes, regime change, or Humphreysan rights, tend to attract people with relatively intense preferences for these causes. We may conjecture that these people are the ones that are also more active as citizens (Norris, 2011). What we suspect, but have not been able to establish to date, is that joining a community of other activists, by joining a Facebook page, produces independent causal effects on the joiners.

In our study, we randomly assign people to either a control group or to two experimental groups that receive an encouragement to join (follow) a campaign. People who are given an encouragement elect whether to take it or ignore it. For most experimental studies, the stage of people electing to take the prescribed treatment is of no direct interest. For us it is: it shows the type of person who responds to a recruitment effort. In our case, it also shows whether the type of respondent who elects to follow a social media coordinated campaign is 

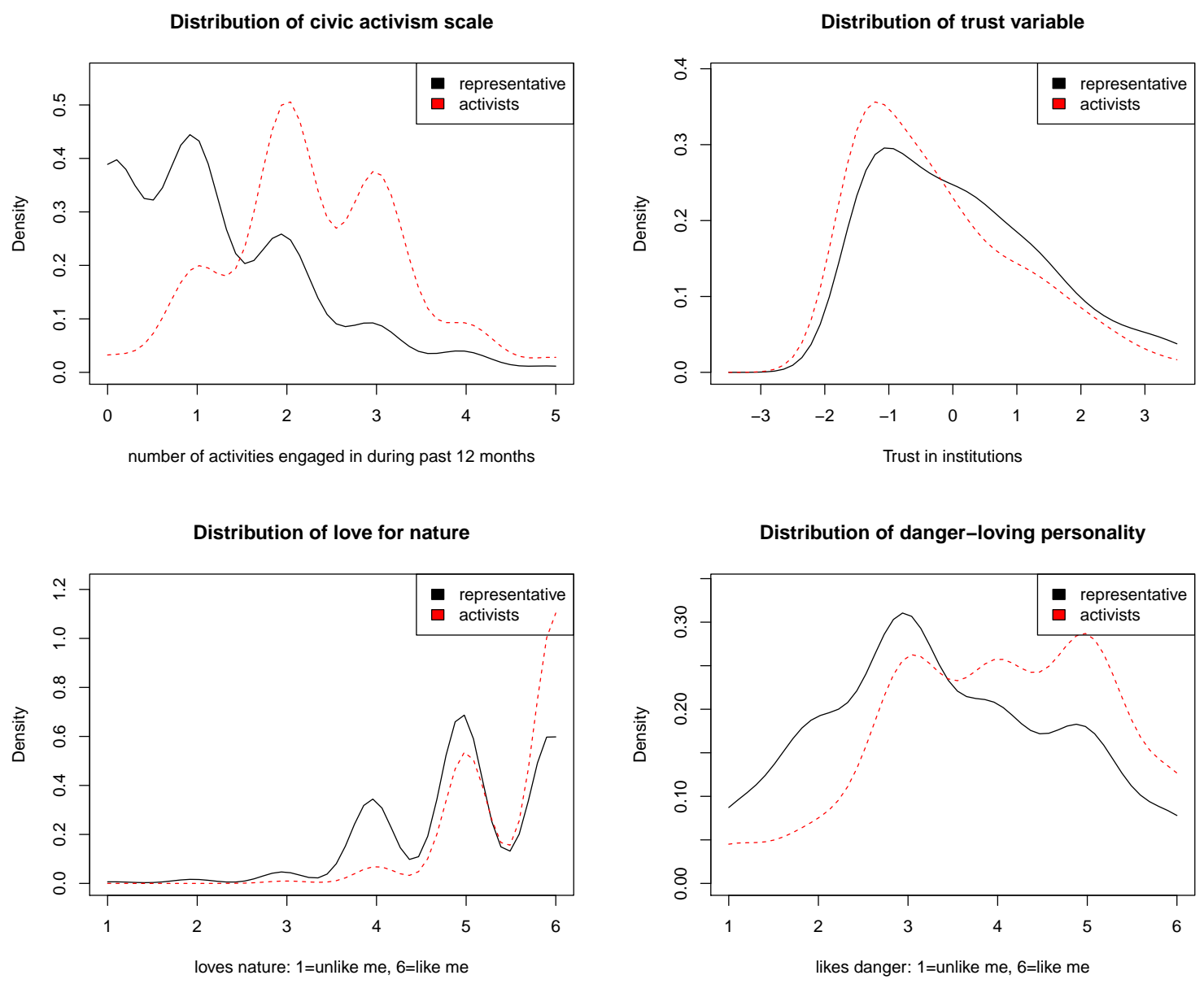

Figure 1: Comparing the type of respondents attracted by a green page, ZaDaOstane, to a representative sample of $F B$ users on previous civic activism, attitudes, and personality traits. Solid line - representative, broken line - activists.

systematically different from the type of respondent who would sign up to follow an email newsletter campaign.

Contrary to what we expected, the Facebook and newsletter campaigns attracted the same share of respondents to sign-up (58\% in the Facebook group compared to and $57 \%$ in the newsletter group).

Figure 2 shows that some of the differences observed in Figure 1 between the representative 

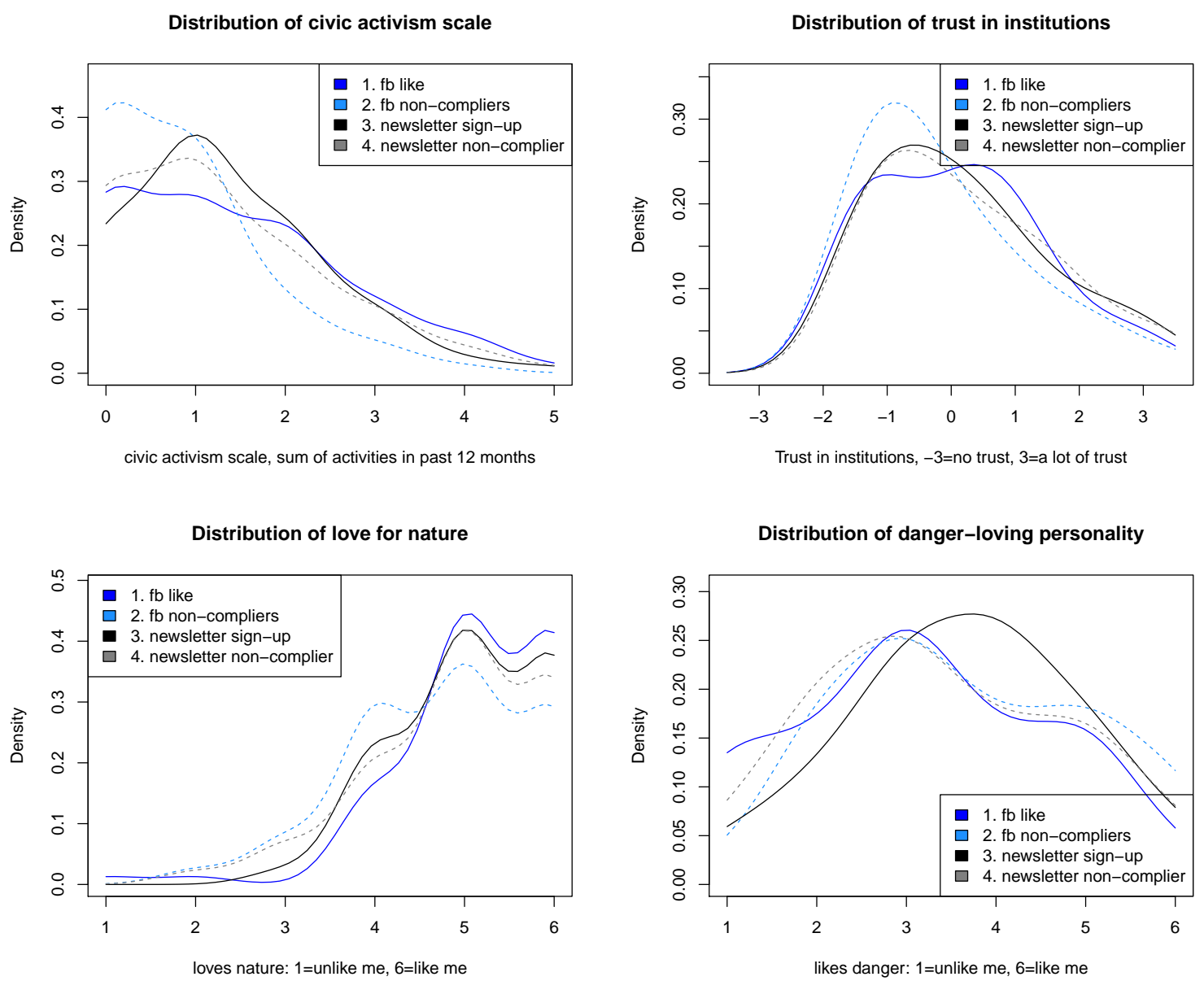

Figure 2: Comparing the profiles of respondents who join our Facebook campaign when invited to do so to those who decide not to join, to respondents who decide to follow the newsletter campaign and those who decide not to sign up, solid line: compliers; dashed: non-compliers.

and the activist samples also predict whether a respondent joins a Facebook or newsletter campaign on environmental issues if invited to do so. Appendix Table A4 models selection on observable pre-treatment covariates into liking either the Facebook campaign or signing up to the newsletter, for the representative sample, systematically based on the covariates recorded in wave 1 . The most important variables that positively predict whether a respondent chooses to follow the Facebook campaign are educational attainment, an adventurous personality and prior civic activism. Using randomization inference we find that, taken together, the 
differences on observable attributes between subjects who take the encouragement to like the Facebook page and subjects who take the encouragement to sign up to a newsletter are not significant (randomization inference-based p-value of 0.62 ; see Figure A1 in the Online Appendix).

Overall, the findings are hence consistent with the first part of Hypothesis 1. Members with predilections for the cause are especially likely to respond to recruitment appeals. However, there is little evidence for the second part of the Hypothesis, that a networked campaign exerts a stronger pull than the non-networked campaign as both campaigns recruited a similar number of participants. While the Facebook campaign was selective on education, and prior activism, and the email campaign was not, taken together the observable differences between email newsletter sign-ups and Facebook followers were not significant. This is the first benchmark finding of this nature that we are aware of.

What we cannot see from these observational data is whether the distinct preferences and self-reported actions of those respondents who are engaged in environmental activist groups are purely a product of selection (Facebook groups attracting respondents who are more active), or whether there is also an independent effect of exposure to the campaign on environmental attitudes and activism. Thus, we do not know whether the differences between respondents who select to be active and those who are inactive are driven by selection-only, or selection, compounded by changes to the joining population. Via the randomly assigned encouragement to join the Facebook page or sign-up to the email newsletter, based around a new initiative to protect the remaining undeveloped Black Sea beaches, we intend to identify the causal effects of following such a campaign. The next section reports our experimental results. 


\section{Experimental Evidence}

\subsection{Do social media campaigns have a causal impact: attitudinal measures}

The Facebook page ZaMoreto featured some of the behavior we think is theoretically relevant for influence to occur. In Appendix Figure A8 we include snapshots from the page, or from users' shares of the page. They include comments such as "we are awake", "this is a resource we must protect", "only citizens can protect what is left", and an example of a user's Facebook friend responding to a plea to use wild nature as a tourism resource with an example of another campaign that is already doing this for the mountains. We next check if this type of online behaviour produced any transformative effect on users' attitudes.

Because we randomly encourage subjects to follow the campaign either via Facebook or Email newsletter, or assign them to control, we can identify the causal effects of the encouragement on their attitudes. Issues of panel attrition, and covariate balance are addressed in detail the Appendix (see Figures A3 and A4, as well as Table A3). As shown in Table A3, two out of 23 covariates show some imbalances between the three experimental conditions in the post-treatment survey wave. However, a randomization-inference based test shows that all covariates, taken together, are no more predictive of treatment assignment than were we to re-assign all subjects to the three experimental groups under the assumption that there is no effect of the pre-treatment covariates on treatment assignment for any subject $(\mathrm{p}=0.32)$. Moreover, attrition rates between the pre- and post-treatment waves do not vary significantly between experimental groups (randomization-inference-based p-value of 0.51 ). ${ }^{7}$ While we cannot test if the groups, post-treatment and post-attrition, differ on unobservables, we

\footnotetext{
${ }^{7}$ The large-sample p-value based on a joint f-test following a linear regression of missigness on experimental conditions is 0.78 .
} 
purposefully deployed encouragements that we thought would not deter or encourage survey participation in the future.

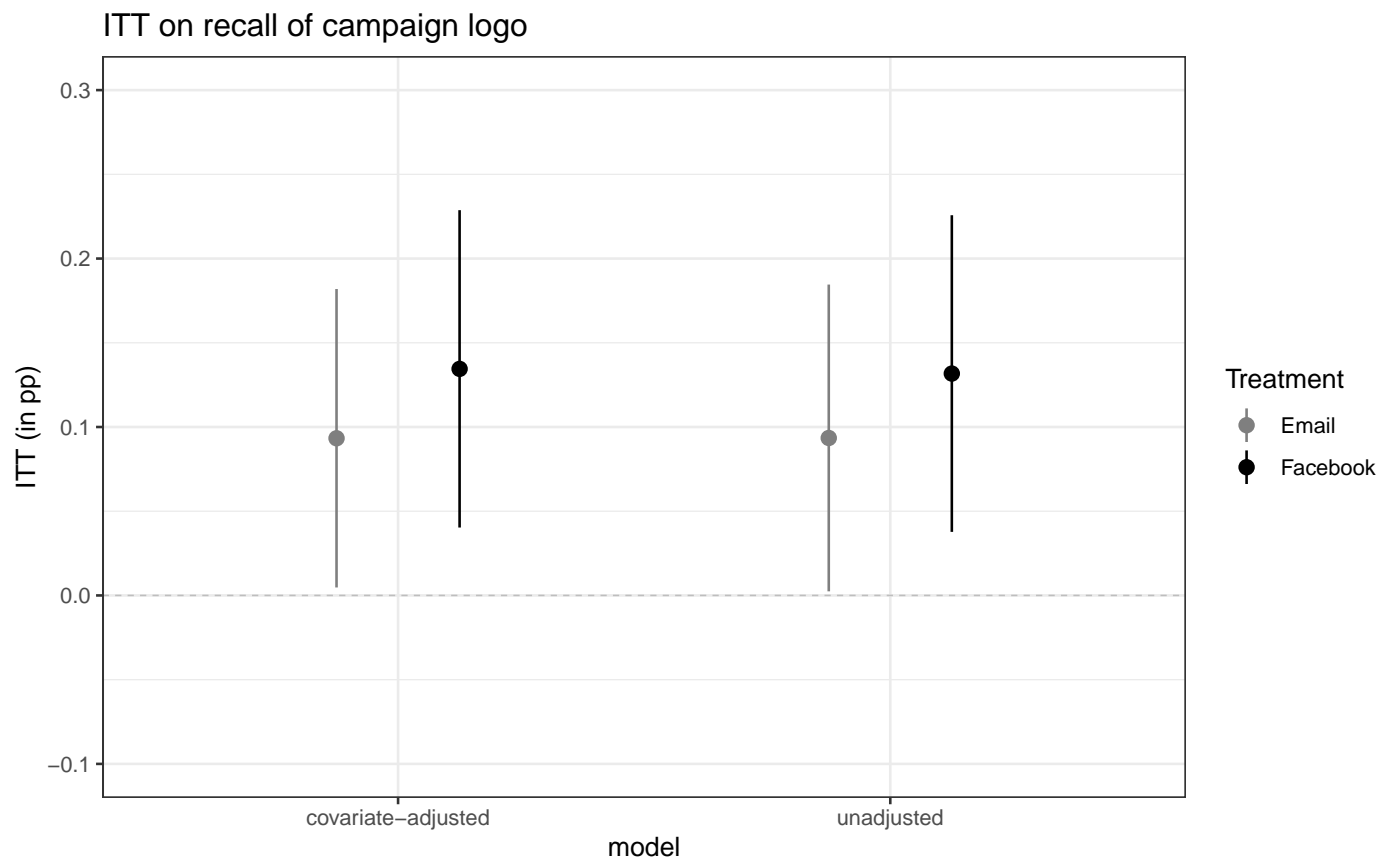

Figure 3: Manipulation Check: ITT of encouragement to like to Facebook page and sign-up to the newsletter on campaign logo recall, unadjusted and covariate-adjusted, 95\% CIs

Figure 3 displays our manipulation check: Are subjects who were encouraged to like the Facebook page and subjects who were encouraged to subscribe to the newsletter more likely to recall the campaign logo of the environmental NGO? Figure 3 shows the Intent-to-Treat (ITT) effects of the encouragement to like the Facebook page, and of being encouraged to sign-up to the newsletter on logo recall, once without adjustment for pre-treatment covariates and once covariate-adjusted.

We find that being encouraged to like the Facebook page made subjects 13 percentagepoints more likely to recall the campaign logo, a large and statistically significant effect. There is also a substantial, statistically significant effect of the newsletter encouragement on logo recall, albeit with 9 percentage-points, not as large. This shows that subjects in both 
treatment conditions are significantly more likely to recall the campaign logo than subjects in the control group, and that the manipulation succeeded, a pre-condition for influencing subjects' attitudes and perceptions.

We now exploit the exogenous nature of experimental assignment to the treatment groups to draw conclusions about the effects of the two campaign methods on attitudes and perceptions related to the environment and to civic activism. In the post-treatment wave, we measure attitudes and perceptions on scales ranging from 0-2, 0-3, and 0-4. The English translations of the questions are available in Appendix Figure A2. For ease of interpretation, we rescale each measure to have a mean of 0 , and a standard deviation of 1 in the control group. That means the treatment effects of the campaign conducted via Facebook or Email Newsletter can then be interpreted as the effects in standard deviations the campaigns would have among an untreated population. Power simulations disaplayed in Appendix Table A1 and Figure A2 show that our field experiment is powered at $68 \%$ to identify small, but meaningful treatment effects of 0.25 standard deviations, and at $100 \%$ to identify moderate to large effects of 0.50 standard deviations.

We first report evidence on the effects we expected to see based on our theoretical considerations on social interactions, perceived outcomes of activism, knowledge and perceived importance of the environment. ${ }^{8}$ Figures 4,5 and 6 plot the covariate-adjusted Intent-to-Treat Effects of treatment assignment, the encouragement to either like the Facebook campaign page or sign-up to the campaign email newsletter, on self-reported outcomes, estimated using linear regression with robust standard errors (HC2). To correct for differential probabilities of assignment to experimental conditions between the representative and activist samples, we always use Inverse Probability Weights (IPW) to weight to the inverse of the probability of assignment to the experimental condition the subject is in. While Figure 4 shows whether

\footnotetext{
${ }^{8}$ We rely on self-reported attitudes, perceptions and behaviors because we were in no position to collect behavioral data on the Facebook sample, which was spread out across the country.
} 


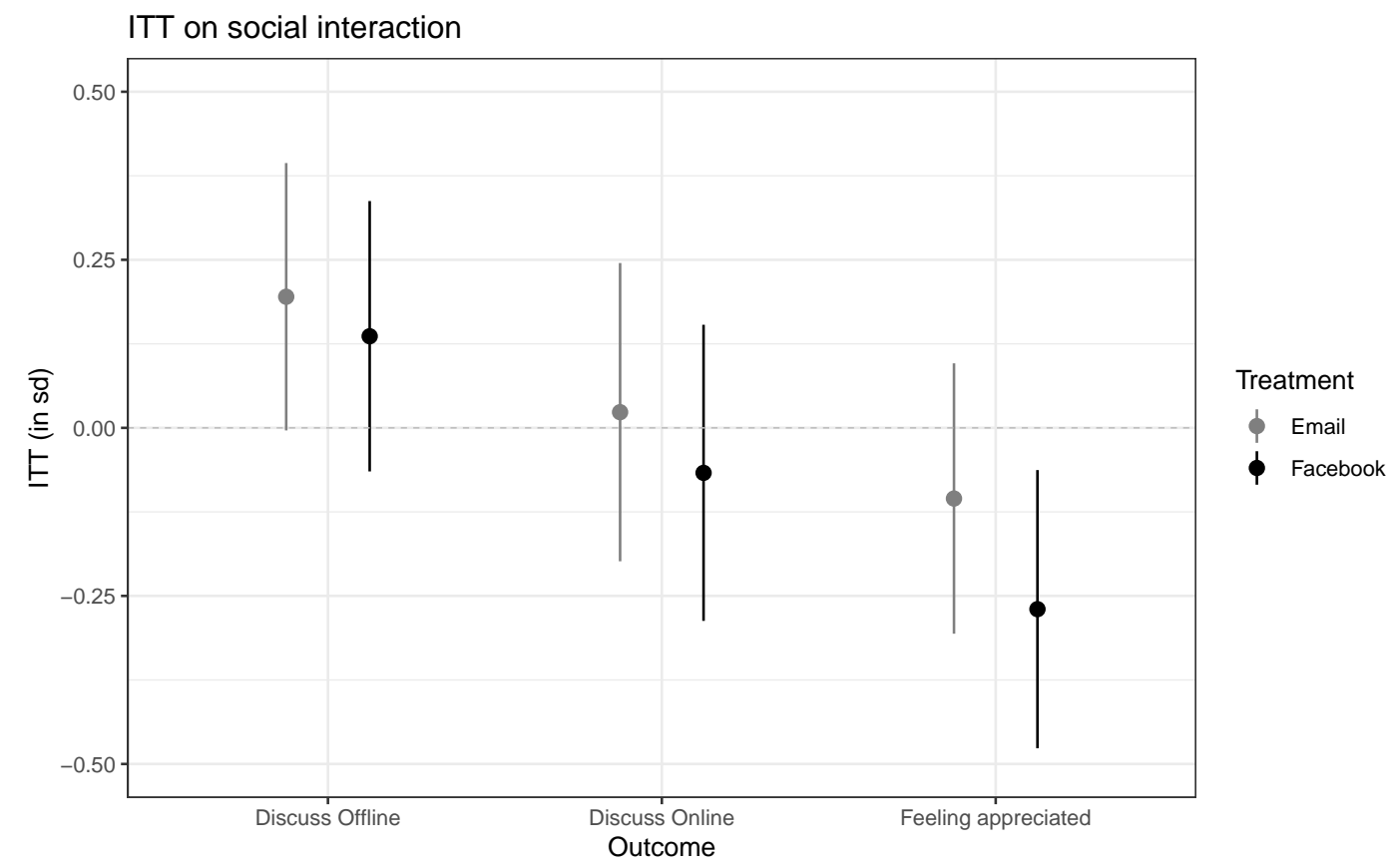

Figure 4: Effect of treatment assignment (ITTs) on social interaction - covariate-adjusted, $95 \%$ CIs

being encouraged to follow a campaign affected interactions with others on social media and offline, Figure 5 displays the effects of treatment assignment on attitudinal outcomes related to civic engagement. Figure 6 plots the effects on perceived issue importance and environmental knowledge.

The corresponding covariate-adjusted Complier Average Causal Effects (CACE), based on IV regression with robust standard errors (HC2), where the randomly assigned encouragements are used as instruments for the endogenous decisions to like the Facebook page or to sign up to the newsletter, are displayed in Figure 7. In order to identify the CACE, we need to assume that the randomly assigned encouragements only affect outcomes via liking the page or signing up to the newsletter, not via other, alternative channels. ${ }^{9}$

\footnotetext{
${ }^{9}$ The corresponding unadjusted ITT and CACE effects are displayed in Tables A5, A6 and A7 in the Appendix.
} 


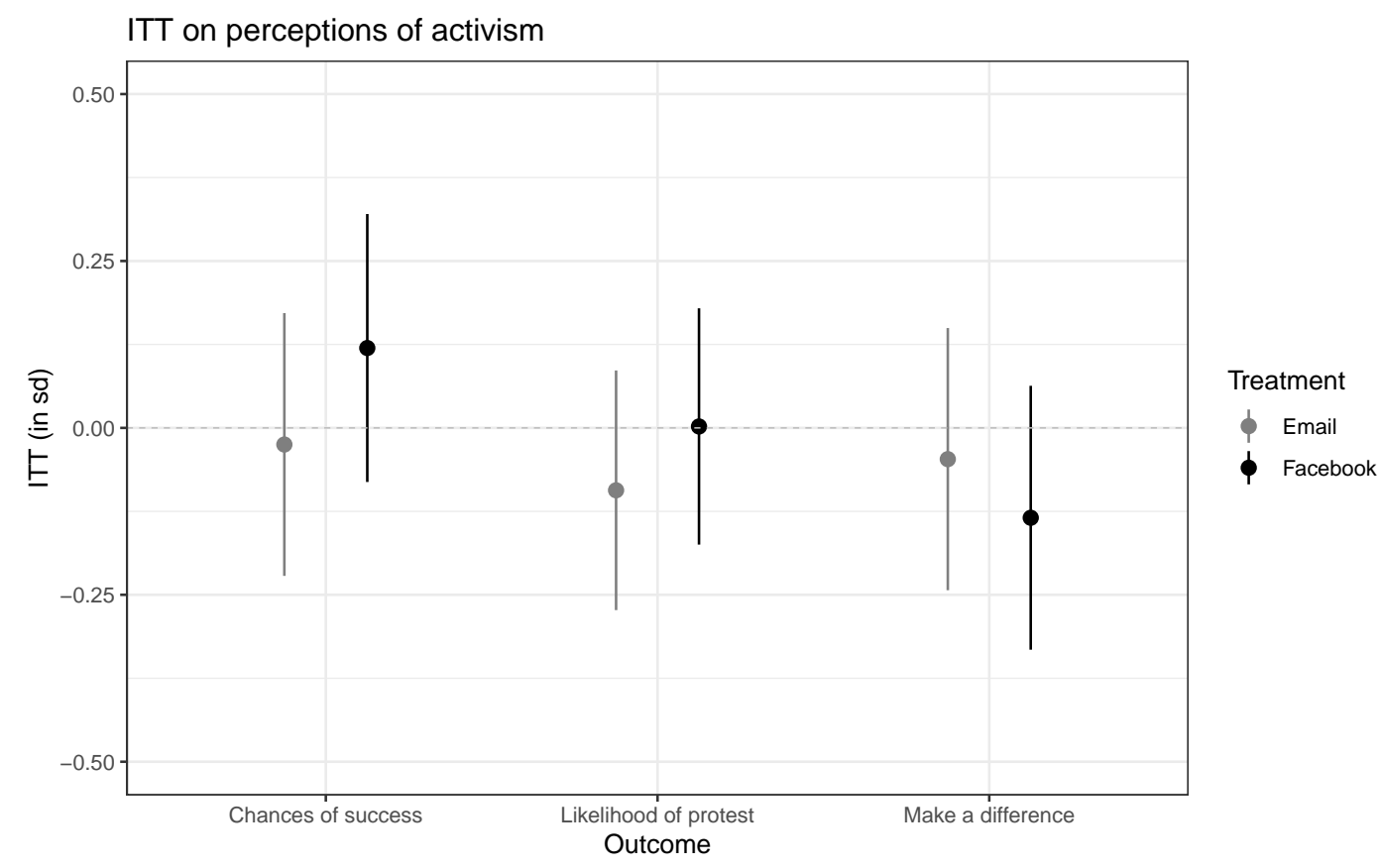

Figure 5: Effect of treatment assignment (ITTs) on activism-related attitudes - covariateadjusted, $95 \% \mathrm{CIs}$

The main result from this study is that both the Facebook and the Email campaign conducted over eight weeks had only minimal effects on attitudes and perceptions related to the environment and to civic activism. Most estimated effect sizes are very small (in the region of $-0.12-0.12$ standard deviations), and out of 16 estimates, 6 have a positive sign, and 10 have a negative sign. Hence, overall, the campaign was ineffective at changing perceptions and attitudes, no matter whether conducted via Facebook or email.

There is some weak evidence, not statistically significant by any conventional standard, that the newsletter $(\mathrm{p}=0.06)$ and the Facebook campaign $(\mathrm{p}=0.18)$ might have positively affected discussion about the environment with friends in real life. But both campaigns made little difference to subjects' discussion behavior online. The ITT estimates, -0.07 and 0.02 standard deviations, are very small, and not statistically significant.

There is no evidence that liking the Facebook page positively affected other behavioral, 


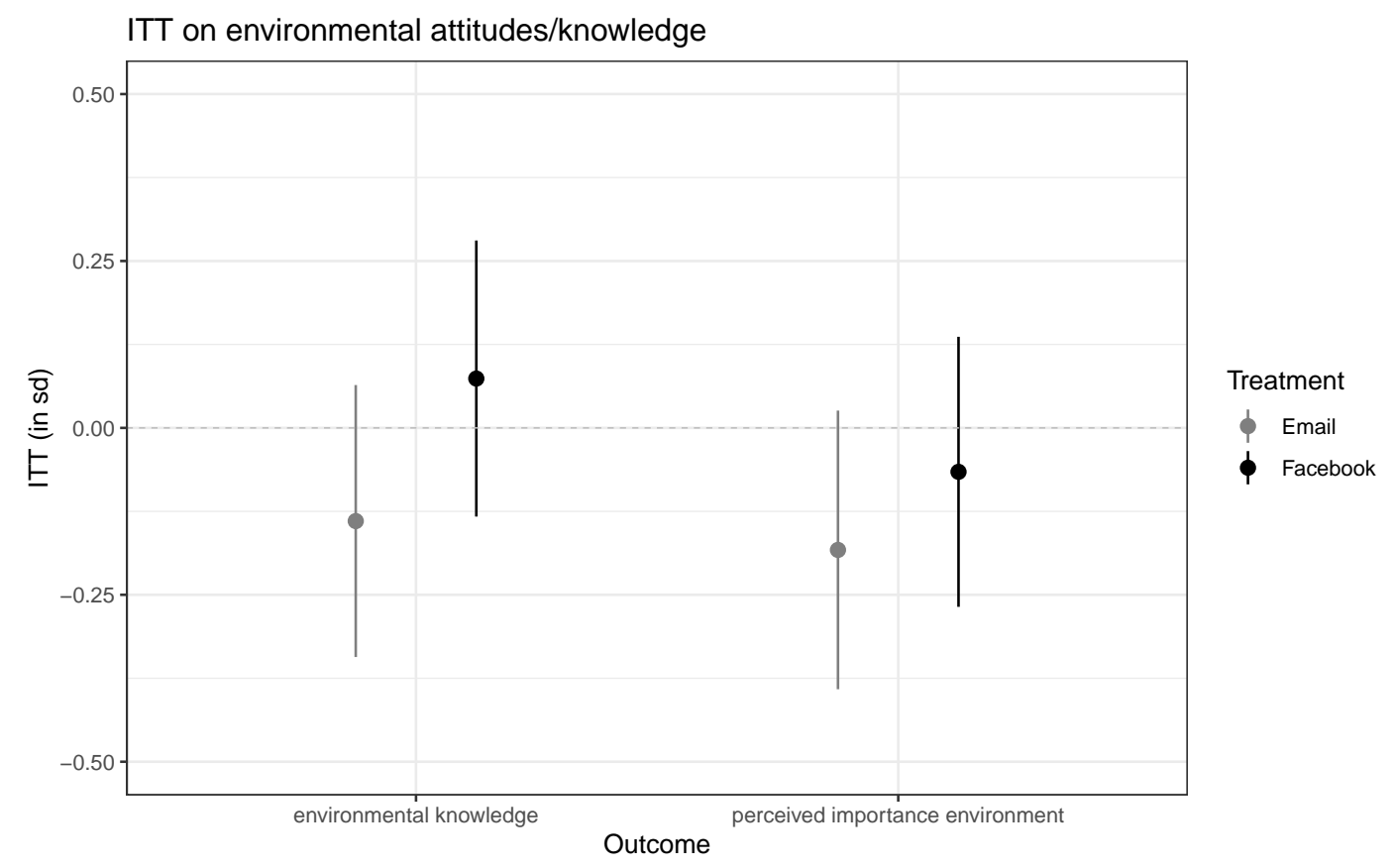

Figure 6: Effect of treatment assignment (ITTs) on environmental attitudes and knowledge - covariate-adjusted, $95 \%$ CIs

attitudinal or knowledge outcomes in Figures 5 and 6: Subjects are neither more likely to perceive that they are able to make a difference, nor do they report a higher probability of participating in environmental protests in the future. Surprisingly, subjects who followed the Facebook campaign think that others are less likely to appreciate those who campaign (see Figure 4) and we also report a negative estimate of the email campaign on issue importance, which is consistent with Butler and Hassell (2018)'s finding from an email experiment in the United States.

Figure 8 shows that effects do not differ between the representative and the activist samples. Due to ceiling effects one might expect that following a campaign should have larger effects on the attitudes, perceptions, and environmental knowledge of the non-activist population. However, we do not find that the effects differ. Overall, there is hence weak or non-existent support for Hypothesis 2 in its different parts. The environmental campaign conducted via 


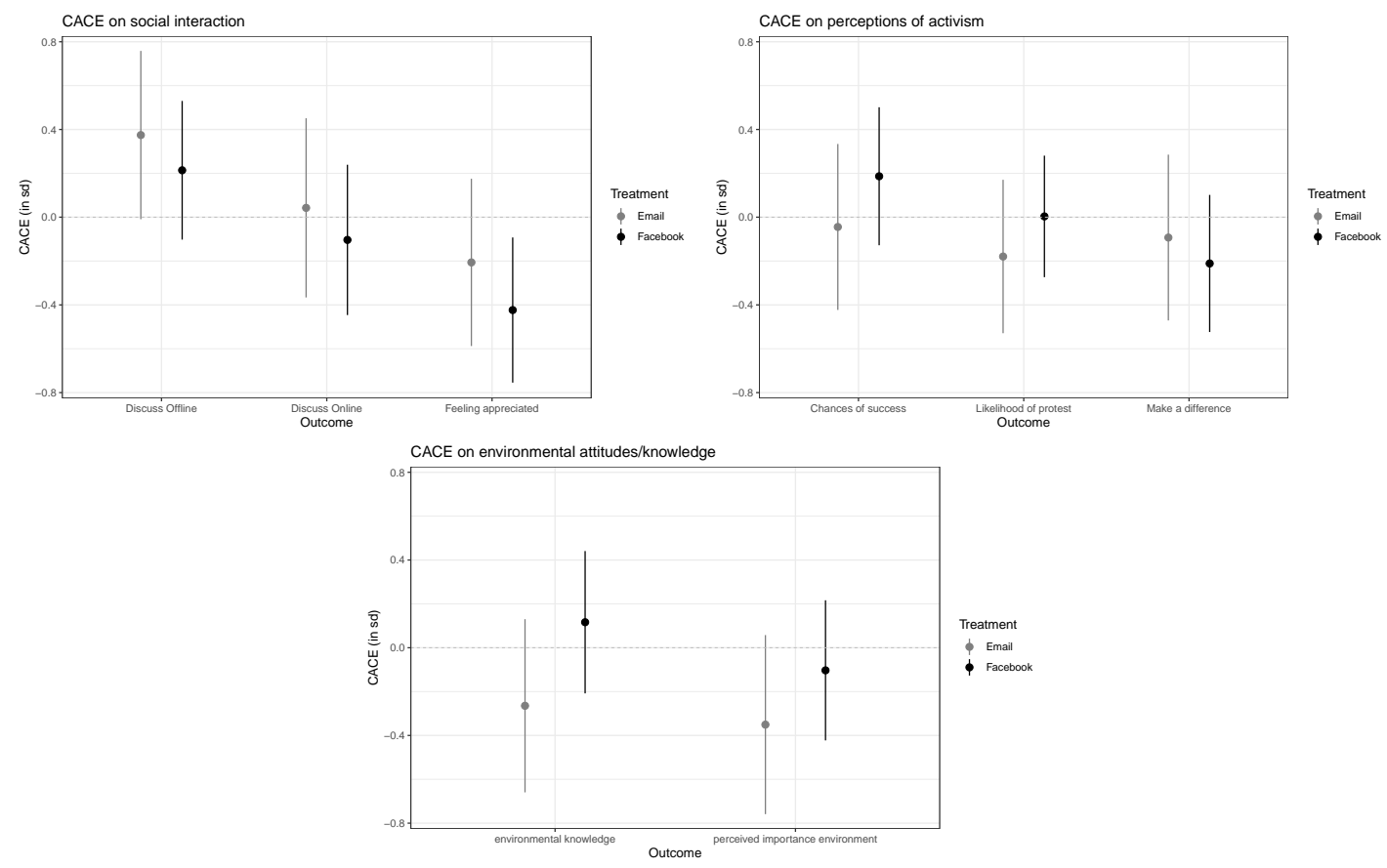

Figure 7: CACEs of liking the Facebook page and subscribing to the newsletter on attitudinal outcomes - covariate-adjusted, 95\% CIs

Facebook did not change attitudes and perceptions related to civic engagement, nor did it positively affect perceptions of internal or external efficacy .

\section{Conclusion}

In line with expectations, we show that activists on social media sites are unrepresentative compared to the general Facebook population, specifically in relation to education, social connections, personality traits and previous civic activism. We also show that those who take up the encouragement and follow the campaign via Facebook are more educated, and more likely to have been active before. Thus, the network draws in the more active types.

What is less well understood, is whether these differences are due to selection effects (activists selecting into online communities) or if social media independently affect attitudes 

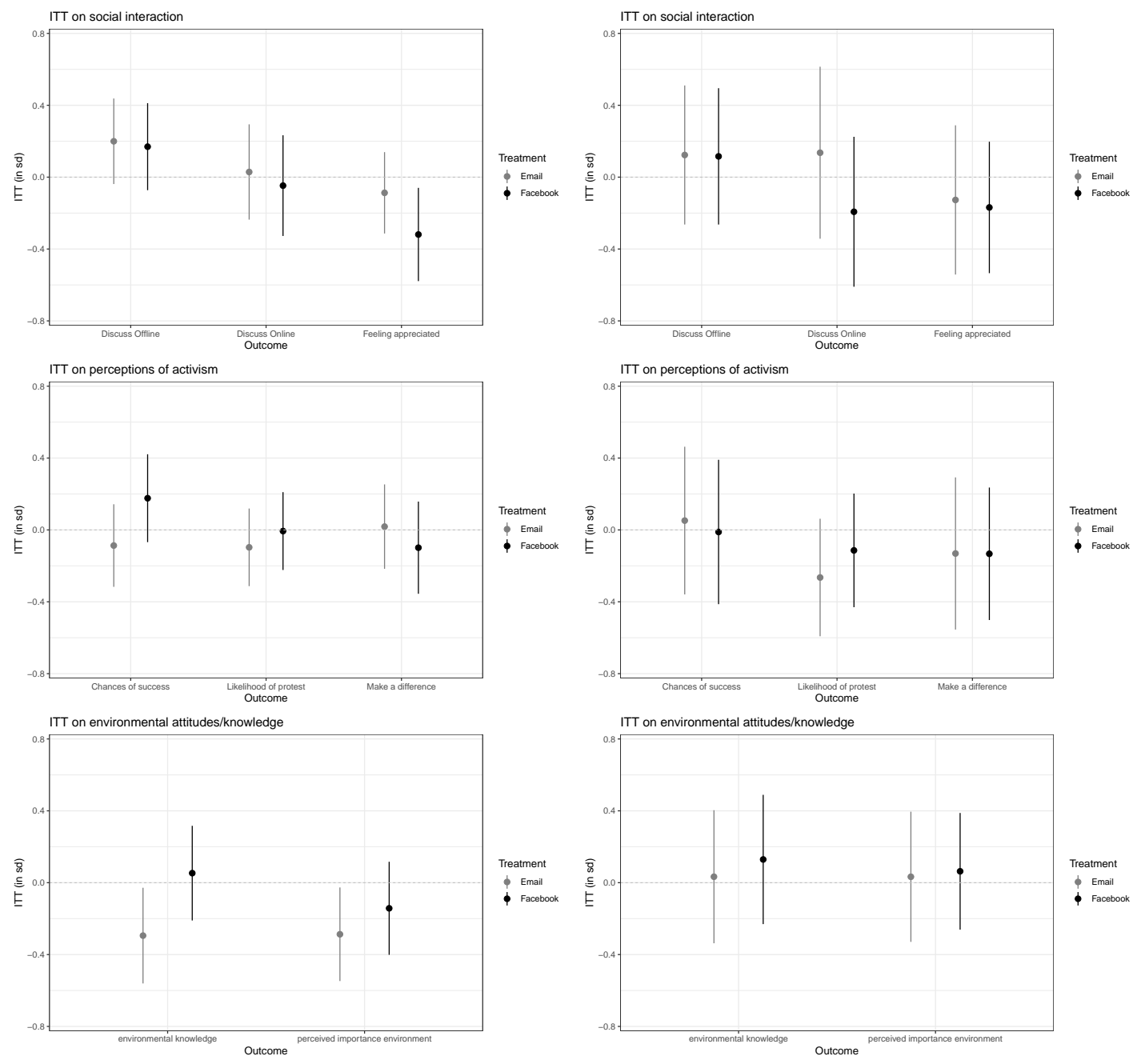

Figure 8: ITTs on representative sample (column 1) ITTs on activist sample (column 2) covariate-adjusted, $95 \%$ CIs

and preferences of citizens who use them. Our results allow for some, albeit preliminary, conclusions to be drawn. Against expectations, the networked campaign did not attract a larger number of participants than the campaign run via an online newsletter, and overall, there were few observable differences between subjects who decided to follow a networked compared to a non-networked campaign. Finally, and most importantly, we find little evidence that the social media campaign shaped how citizens and activists saw a cause or how they related to the campaign. 
While our results are hardly generalizable to mass mobilization in the context of high salience events such as revolutions, or mobilization in response to specific government actions, they speak to the difficulties a large number of non-governmental organisations face when attempting to inform, organize and mobilize citizens around causes such as the environment or mid-level corruption. While social media is an effective means of organizing, our experiment suggests that messages that are shared on Facebook groups in order to inform and mobilize citizens had little lasting impact beyond "likes" and "shares". Thus, in the language of Bennett and Segerberg (2012), our intervention may have induced some connective online action, but that hardly translated into measurable gains from a collective action perspective, as measured by the desire to take part in protest. Perhaps this is due to the fact that our campaign was relatively modest, and did not concern some of the big issues agitating digitally-connected mass audiences (Tufekci, 2017).

The null results from this field experiment do not stand alone. They are in accordance with other work that speaks to the limits of social media in influencing attitudes and behaviors. Earlier work shows that public tweets are ineffective at affecting online activism related to environmental causes (Coppock, Guess and Ternovski, 2016), that signing up to Facebook had - if at all - negative effects on self-reported electoral participation (Theocharis and Lowe, 2016), and that Facebook ads were ineffective at persuading voters (Broockman and Green, 2014). We also have confidence in our experimental results because the data show the observational patterns and associations between activism and background attributes that we would expect based on theory and earlier work. While the intervention did not take place in a context of mass mobilization, the salience of the environmental issue in Bulgaria is high, and the environmental activists we collaborated with expected the campaign to be effective. We also show that the intervention was memorable to respondents. Facebook users who took the encouragement to follow the campaign were 21 percentage-points more likely to recall 
it than users allocated to the control group. Overall, this study adds to a growing body of work showing that it is more difficult than commonly assumed to change political attitudes and behaviours via social media interventions.

Our results are both good and bad news in regard to democratic practice. They are good news because they suggest that growing concerns about campaigns exerting disproportionate influence on citizens' attitudes and opinions on social media may be overstated. In contrast to the expectation that Facebook or other social media can easily make citizens believe in causes that they would not otherwise adhere to, the results of this study show that following a Facebook page on a political issue for multiple weeks did not change citizens' opinions. At the same time, they provide some bad news for civic organisations who would like to engage the general public on important issues of public policy. It appears difficult to turn citizens into activists by providing them with accurate information about policy problems. 


\section{References}

Anderson, Lisa. 2011. "Demystifying the Arab Spring." Foreign Affairs pp. 2-7.

Arceneaux, Kevin and Martin Johnson. 2013. Changing Minds or Changing Channels? Partisan News in an Age of Choice. Chicago, IL: University of Chicago Press.

Bakshy, Eytan, Solomon Messing and Lada A. Adamic. 2015. "Exposure to ideologically diverse news and opinion on Facebook." Science 348(6239):1130-1132.

Barberá, Pablo. 2014. "How Social Media Reduces Mass Political Polarization: Evidence from Germany, Spain, and the U.S.” Job Market Paper, New York University.

Barberá, Pablo, John T. Jost, Jonathan Nagler, Joshua A. Tucker and Richard Bonneau. 2015. "Tweeting from left to right: Is online political communication more than an echo chamber?" Psychological science 26(10):1531-1542.

Bennett, Lance and Alexandra Segerberg. 2012. "The Logic of Connective Action." Information, Communication and Society 15(5):739-768.

Bode, Leticia, Emily Vraga, Porismita Borah and Dhavan Shah. 2014. "A New Space for Political Behavior: Political Social Networking and its Democratic Consequences." Journal of Computer-Mediated Communication 19:414-429.

Bond, Robert M., Christopher J. Fariss, Jason J. Jones, Adam D. I. Kramer, Cameron Marlow, Jaime E. Settle and James H. Fowler. 2012. "A 61-million-person Experiment in Social Influence and Political Mobilization." Nature 489:295-298.

Boulianne, Shelley. 2015. "Social media use and participation: a meta-analysis of current research." Information, Communication $\mathcal{E}$ Society 18(5):524-538. 
Bratton, Michael and Nicholas van de Walle. 1992. "Popular Protest and Political Reform in Africa." Comparative Politics 24:419-42.

Broockman, David E. and Donald P. Green. 2014. "Do online advertisements increase political candidates' name recognition or favorability? Evidence from randomized field experiments." Political Behavior 36(2):263-289.

Butler, Daniel M. and Hans Hassell. 2018. "On the Limits on Officials' Ability to Change Citizens' Priorities: A Field Experiment in Local Politics." American Political Science Review Online First:https://doi.org/10.1017/S0003055418000473.

Coppock, Alexander, Andrew Guess and John Ternovski. 2016. "When treatments are tweets: A network mobilization experiment over twitter." Political Behavior 38(1):105128.

Diamond, Larry. 2002. "Thinking About Hybrid Regimes." Journal of Democracy 13:21-35.

Fowler, James, Michael Heaney, David Nickerson, John Padgett and Betsy Sinclair. 2011. "Causality in Political Networks." American Politics Research 29(2):437-480.

Gerber, Alan S., Donald P. Green and Christopher W. Larimer. 2008. "Social Pressure and Voter Turnout: Evidence from a Large-Scale Field Experiment." American Political Science Review 102:33-48.

Gohdes, Anita. 2014. "Repression in the Digital Age: Communication Technology and the Politics of State Violence." Doctoral Dissertation, University of Mannheim.

González-Bailón, Sandra. 2014. Online Social Networks and Bottom-up Politics. In Society and the Internet: How Networks of Information and Communication are Changing Our Lives, ed. Mark Graham and William Dutton. London, UK: Oxford. 
Goodwin, Jeff. 1997. "The Libidinal Constitution of a High- Risk Social Movement: Affectual Ties and Solidarity in the Huk Rebellion." American Sociological Review 62(1):53-69.

Gunitsky, Seva. 2015. "Corrupting the Cyber-Commons: Social Media as a Tool of Autocratic Stability." Perspectives on Politics 13(1):42-54.

Han, Hahrie. 2016. "The organizational roots of political activism: Field experiments on creating a relational context." American Political Science Review 110(2):296-307.

Howard, Marc Morje. 2003. The Weakness of Civil Society in Post-Communist Europe. New York: Cambridge University Press.

Howard, Philip, Sheetal Agarwal and Muzammil Hussain. 2011. "When Do States Disconnect Their Digital Networks? Regime Responses to the Political Uses of Social Media." The Communication Review 14(3):216-232.

Jost, John T., Pablo Barberá, Richard Bonneau, Melanie Langer, Megan Metzger, Jonathan Nagler, Joanna Sterling and Joshua A. Tucker. 2018. "How Social Media Facilitates Political Protest: Information, Motivation, and Social Networks." Political Psychology 39(1):85118.

Kitts, James. 2000. "Mobilizing Black Boxes: Social Networks and Participation in Social Movement Organization." Mobilization 5:241-57.

Klandermans, Bert. 2002. "How Group Identification Helps to Overcome the Dilemma of Collective Action." American Behavioral Scientist 45(5):887-900.

Klandermans, Bert and Dirk Oegema. 1987. "Potentials, Networks, Motivations and Barriers: Steps toward Participation in Social Movements." American Sociological Review 52(4):51931. 
Lieberman, Evan S., Daniel N. Posner and Lily L. Tsai. 2014. "Does Information Lead to More Active Citizenship? Evidence from an Education Intervention in Rural Kenya." World Development 60:69-83.

Margetts, Helen, Peter John, Scott Hale and Taha Yasseri. 2016. Political Turbulence. How Social Media Shape Collective Action. Princeton: Princeton University Press.

Margetts, Helen Z., Peter John, Scott A. Hale and Stephane Reissfelder. 2015. "Leadership without Leaders? Starters and Followers in Online Collective Action." Political Studies 63(2):278-299.

Messing, Solomon, Eytan Bakshy and Andrew Fiore. 2014. "Social Influence and Participation: How Socially Shared Content Boosts Civic Participation.” Working Paper, Facebook Research Team, Menlo Park.

Nickerson, David. 2007. "Does Email Boost Voting Turnout?" Quarterly Journal of Political Science 2:369-79.

Norris, Pippa. 2011. Digital Divide? Civic Engagement, Information Poverty and the Internet Worldwide. New York: Cambridge University.

Olson, Mancur. 1971. The Logic of Collective Action: Public Goods and the Theory of Groups. Cambridge, MA: Harvard University Press.

Putnam, Robert. 2000. Bowling Alone: The Collapse and Revival of American Community. New York: Simin and Shuster.

Settle, Jamie. 2014. "Newspaper to News Feed: How Social Media Has Changed the Way We Access News and Discuss Politics." Manuscript, College of William and Mary.

Tarrow, Sidney. 1998. Power in Movement: Social Movements and Contentious Politics. New York: Cambridge University Press. 
Theocharis, Yannis and Will Lowe. 2016. "Does Facebook Increase Political Participation? Evidence from a Field Experiment." Information, Communication and Society 19(10):1465-1486.

Tufekci, Zeynep. 2017. Twitter and Tear Gas: The Power and Fragility of Networked Protest. New Haven, CT: Yale.

Tufekci, Zeynep and Christopher Wilson. 2012. "Social Media and the Decision to Participate in Political Protest: Observations From Tahrir Square." Journal of Communication 62(2):363-379.

Vaccari, Cristian, Augusto Valeriani, Pablo Barberá, Richard Bonneau, John T. Jost, Jonathan Nagler and Joshua Tucker. 2015. "Political Expression and Action on Social Media: Exploring the Relationship Between Lower- and Higher-Threshold Political Activities Among Twitter Users in Italy." Journal of Computer-Mediated Communication 20(2):221-239.

Verplanken, Bas and Rob Holland. 2002. "Motivated decision making: effects of activation and self- centrality of values on choices and behavior." Journal of Personality and Social Psychology 82(3):434-447. 